\title{
Balloon angioplasty with secondary stenting for chronically occluded abdominal aorta in a high-risk patient
}

\author{
Mohmmadtokir Mujtaba, ${ }^{1}$ Lovely Chhabra, ${ }^{2}$ Abdulrahman M Abdulbaki, ${ }^{3}$ \\ Immad Sadiq ${ }^{1}$
}

Correspondence to Dr Lovely Chhabra, lovids@hotmail.com

Accepted 7 July 2014

\section{CrossMark}

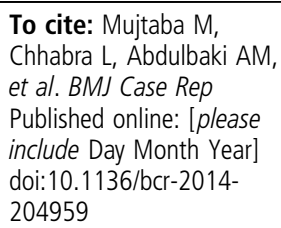

\section{${ }^{1}$ Department of Cardiology,
Hartford Hospital, University of \\ Department of Cardiology,
Hartford Hospital, University of Connecticut School of Medicine, Hartford, \\ Connecticut, USA ${ }^{2}$ Hartford Hospital, University of Connecticut School of Medicine, Hartford, \\ Connecticut, USA \\ ${ }^{3}$ Hartford Hospital, Hartford Connecticut, USA}

DESCRIPTION

A 64-year-old man with history of hypertension, coronary artery disease with coronary bypass was referred to our institution for further evaluation of disabling claudication. Previous history was significant for acute limb ischaemia mandating an emergent thromboembolectomy of his aortoiliac vessels. However, his symptoms persisted and he was subsequently referred to us for further management.

Ankle brachial index (ABI) was 0.51 on right lower extremity (RLE) and 0.48 on the left lower extremity (LLE). With exercise, the ABI worsened to 0.28 on the RLE and 0.43 on the LLE. Further workup with CT angiography revealed a totally occluded abdominal aorta in the infrarenal segment just distal to inferior mesenteric artery (IMA) and extending to common iliac arteries bilaterally (figure 1A). The external iliac arteries (EIA) were patent but severely diseased in their proximal segments. The common femoral arteries (CFA) were patent with moderate disease on the right and minimal disease on the left. After a well-informed discussion with the patient, we planned for an abdominal aortography and intervention on the occluded vascular segments.

Abdominal aortography, selective IMA angiography and selective bilateral angiography of the hypogastric arteries were performed. Notable angiographic findings were patent suprarenal aorta with patent bilateral renal arteries, occluded infrarenal aorta, critical IMA stenosis (99\%) at the ostium, totally occluded bilateral common iliac arteries, and patent bilateral hypogastric arteries with retrograde flow filling the EIA bilaterally. Bilateral EIA, CFA, profunda femoris and superficial femoral arteries appeared patent. Percutaneous transluminal angioplasty with stent placement to the distal abdominal aorta and bilateral common iliac arteries were performed. Final angiography revealed a widely patent infrarenal abdominal aorta and bilateral common and external/internal iliac arteries resulting in restoration of grade 3 thrombosis in myocardial infarction (TIMI) blood flow (figure 1B). There was some residual narrowing observed within the distal abdominal prosthesis but was not intervened on, given the restoration of normal blood flow.

There were no immediate postprocedure complications. He was discharged after an uneventful 2-day hospital course. He was counselled regarding behavioural risk factor modification including diet, exercise and smoking cessation. He was discharged on aspirin $325 \mathrm{mg} /$ day and clopidogrel $75 \mathrm{mg} /$ day.
On his 4-week outpatient follow-up, he reported complete resolution of claudication symptoms in both legs. He could walk up to 3 miles without any discomfort as compared to only 10 feet distance prior to this procedure.

Total aortic occlusion is identified in $3-8.5 \%$ of patients presenting with aortoiliac disease. ${ }^{1}$ It is considered class-D disease by TransAtlantic Inter-Society Consensus II (TASC II) classification. ${ }^{2}$ Aortofemoral bypass is considered the treatment of choice with 5-year and 10-year patency rates up to $90 \%$ and $75 \%$, respectively. ${ }^{3-7}$ Extra anatomical bypass is also an option but associated with higher morbidity and shorter patency rates. ${ }^{5} 8$ Despite excellent long-term outcomes, surgery has been associated with a higher perioperative mortality rate estimated from about $1 \%$ to $7 \%$ and a major early complication rate of $9-27 \%$, including sexual dysfunction, ureteral damage, intestinal ischaemia and spinal cord injury. ${ }^{5910}$ Moreover, surgery is not a great treatment option for candidates who carry a high surgical risk of complications from open vascular surgery. Endovascular procedure remains an excellent alternative with short-to-midterm patency rates for focal stenosis approaching close to that of surgery.

Simons et $a l^{9}$ reviewed seven major studies for treatment of mostly focal aortic stenosis and reported primary and secondary patency rates of $83-100 \%$ and 100\%, respectively. Mean follow-up was 12-27 months. For complex or occlusive disease, a recent review of the long-term outcomes treated with endovascular therapy reported primary and secondary patency rates at 4-5 years ranging from $60 \%$ to $86 \%$ and $80 \%$ to $98 \%$, respectively. 810

Besides plaque burden and complexity of the vascular disease, the mode of endovascular therapy may also affect outcomes. Initial experiences with angioplasty are now frequently supplemented with secondary stenting and/or thrombolytic therapy. Direct stenting may allow decreased risk for vessel rupture, procedural time and risk for thromboembolism. ${ }^{11}$ Klonaris et $a l^{4}$ reported primary patency rates of $83-100 \%$ on short-to-midterm follow-up (18-43 months). However in most prior studies, stenting has followed predilation. Future prospective studies are warranted to explore the long-term efficacy of direct stenting procedures. Also, the use of self-expanding versus balloondilated stents remains an issue for debate which needs to be studied in the future prospective investigations. 

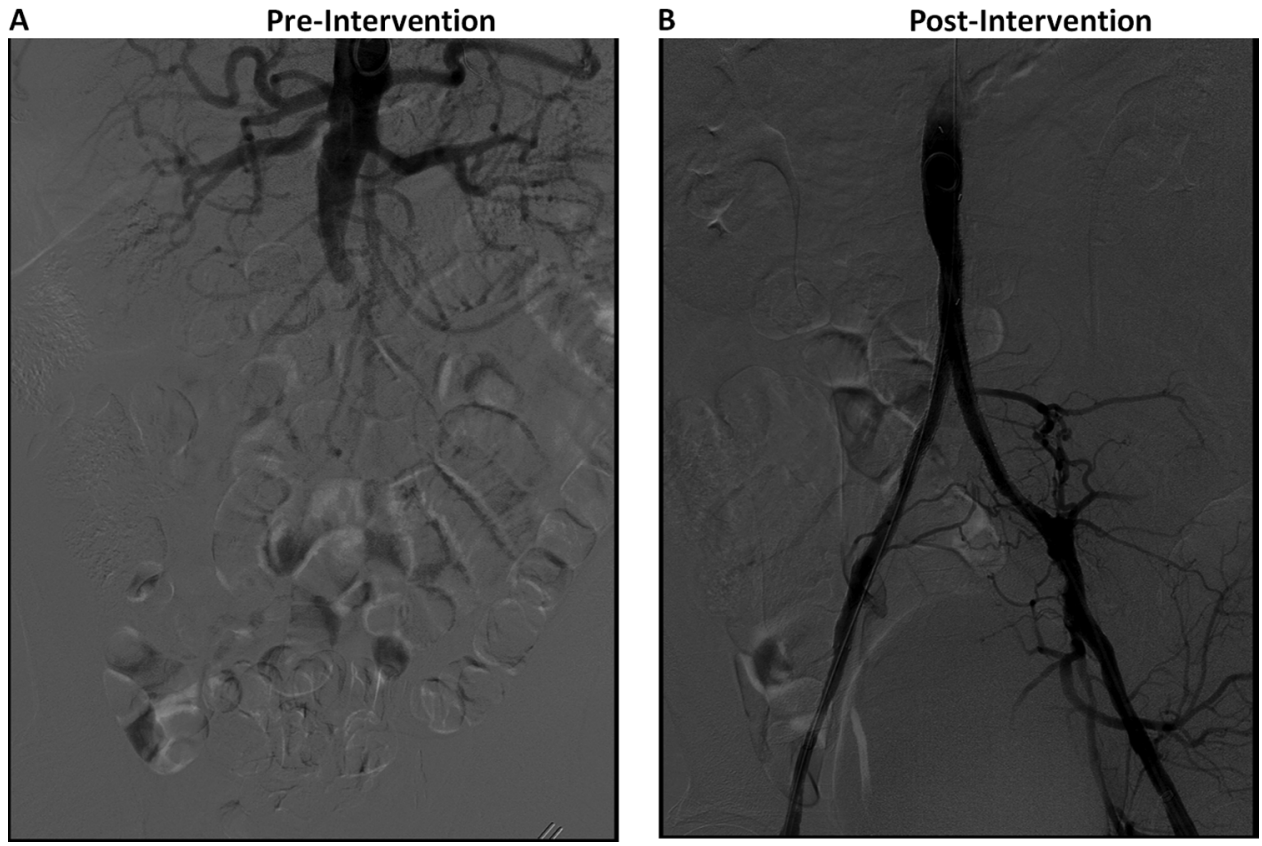

\section{Competing interests None.}

Patient consent Obtained.

Provenance and peer review Not commissioned; externally peer reviewed.

\section{REFERENCES}

$1 \mathrm{Kim}$ T-H, Ko Y-G, Kim U, et al. Outcomes of endovascular treatment of chronic total occlusion of the infrarenal aorta. J Vasc Surg 2011:53:1542-9.

2 Norgren L, Hiatt WR, Dormandy JA, et al. Inter-Society Consensus for the Management of Peripheral Arterial Disease (TASC II). J Vasc Surg 2007;45(Suppl S): S5-67.

3 Moise MA, Alvarez-Tostado JA, Clair DG, et al. Endovascular management of chronic infrarenal aortic occlusion. J Endovasc Ther 2009;16:84-92.

4 Klonaris C, Katsargyris A, Tsekouras N, et al. Primary stenting for aortic lesions: from single stenoses to total aortoiliac occlusions. J Vasc Surg 2008; 47:310-17

5 Ligush J, Criado E, Burnham SJ, et al. Management and outcome of chronic atherosclerotic infrarenal aortic occlusion. J Vasc Surg 1996;24:394-404; discussion 404-5.

6 Dohi T, lida 0, Okamoto S, et al. Mid-term clinical outcome following endovascular therapy in patients with chronic aortic occlusion. Cardiovasc Interv Ther 2013;28:327-32.

7 Burke CR, Henke PK, Hernandez R, et al. A contemporary comparison of aortofemoral bypass and aortoiliac stenting in the treatment of aortoiliac occlusive disease. Ann Vasc Surg 2010;24:4-13.

8 Jongkind V, Akkersdijk GJM, Yeung KK, et al. A systematic review of endovascula treatment of extensive aortoiliac occlusive disease. J Vasc Surg 2010;52:1376-83.

9 Simons PCG, Nawijn AA, Bruijninckx CMA, et al. Long-term results of primary stent placement to treat infrarenal aortic stenosis. Eur J Vasc Endovasc Surg 2006;32:627-33

10 Uberoi R, Tsetis D. Standards for the endovascular management of aortic occlusive disease. Cardiovasc Intervent Radiol 2007:30:814-9.

11 Laganà $\mathrm{D}$, Carrafiello $\mathrm{G}$, Mangini $\mathrm{M}$, et al. Endovascular treatment of steno-occlusions of the infrarenal abdominal aorta. Radiol Med 2006;111:949-58.

Copyright 2014 BMJ Publishing Group. All rights reserved. For permission to reuse any of this content visit http://group.bmj.com/group/rights-licensing/permissions.

BMJ Case Report Fellows may re-use this article for personal use and teaching without any further permission.

Become a Fellow of BMJ Case Reports today and you can:

- Submit as many cases as you like

- Enjoy fast sympathetic peer review and rapid publication of accepted articles

- Access all the published articles

- Re-use any of the published material for personal use and teaching without further permission

For information on Institutional Fellowships contact consortiasales@bmjgroup.com

Visit casereports.bmj.com for more articles like this and to become a Fellow 